\title{
Knowledge on hygiene of rural women of Assam
}

\section{Ingita Gohain and Juliana Sarmah}

Received: 26.08.2019; Revised: 01.11.2019; Accepted: 15.11.2019

See end of the paper for authors' affiliations Ingita Gohain

Department of Extension and Communication Management, College of Community Science, Assam Agricultural University, Jorhat (Assam) India

Email : ingitagohain@gmail.com
ABSTRACT : The study was carried out in the state of Assam (India) with 270 randomly selected rural women of 3 districts, viz., Tinsukia, Nagaon and Barpeta districts to find the existing knowledge level of respondents on hygiene. Majority of the respondents had medium level of knowledge on hygiene in all the districts, viz., Barpeta (67.78\%), Nagaon (67.78\%) and Tinsukia $(61.11 \%)$. It is also found that Nagaon district had the highest percentage $(21.11 \%)$ of respondents with low level of knowledge on hygiene in comparison to the other two districts, i.e. Barpeta (17.78\%) and Tinsukia $(17.78 \%)$.

GEY WORDS: Knowledge, Hygiene, Rural women

- HOW TO CITE THIS PAPER : Gohain, Ingita and Sarmah, Juliana (2019). Knowledge on hygiene of rural women of Assam. Asian J. Home Sci., 14 (2) : 407-410, DOI: 10.15740/HAS/AJHS/14.2/407-410. Copyright@ 2019: Hind Agri-Horticultural Society. 